\title{
Bioactivity of Indigenous Melia azedarach Extracts against the Tomato Leafminer, Tuta absoluta
}

Efat Abou-Fakhr Hammad ${ }^{1}$, Amani Abbass ${ }^{1}$, Muhammad Abbass ${ }^{1}$, Zaynab Mohamad Haidar ${ }^{2}$, Josiane El-Chemali ${ }^{3}$, Youssef Abou Jawdeh ${ }^{4}$ and Ludmilla Ibrahim ${ }^{5}$

1. Department of Plant Protection, Faculty of Agricultural \& Veterinary Sciences, Lebanese University, Dekwaneh, Beirut, Lebanon

2. Ministry of Agriculture, Department of Agriculture Extension Services, Bire Hasan, Beirut, Lebanon

3. Exotica, Department of Ornamental Plants Production, Zouk Mosbeh, Beirut, Lebanon

4. Department of Agriculture, Faculty of Agricultural \& Food Sciences, American University of Beirut, Bliss Street, P.O. Box 11-0236, Riad El-Solh 1107-2020, Beirut, Lebanon

5. Department of Crop Production, Faculty of Agricultural \& Veterinary Sciences, Lebanese University, Dekwaneh, Beirut, Lebanon

\begin{abstract}
Fruit extracts of indigenous Melia azedarach were tested for their insecticidal bioactivity against the tomato leafminer (Tuta absoluta) under laboratory conditions. Tomato plants were exposed to moths, after/before application of treatments. Treatments included: crushed fruit extracts of water $(500,000 \mathrm{ppm}$ and 200,000 ppm), methanol and ethyl acetate (200,000 ppm) with and without mineral oil (2\%); M. azedarach powder extracts (2,000 ppm) in different solvents: water, methanol, ethanol, ethyl acetate, hexane and chloroform; biorational products: neem oil, mineral oil, micronized sulfur and thyme oil. The released moths were removed from treated/untreated plants at $72 \mathrm{~h}$ and effect of treatments on adults, eggs, larvae and pupae were recorded. Results indicated that sulfur caused the lowest number of live moths to be present on treated plants and was not significantly different in its effect from that of M. azedarach extracts and neem oil. Aqueous extracts without and with oil caused the highest \% of dry eggs and were comparable to neem oil. Extracts in the two formulations (crushed fruits and/or powder) caused significant direct effects on immature instars: eggs, early larval instars and pupae. M. azedarach extracts and the tested products also caused indirect effect in form of significant decrease in number of developing the 3rd larval instars and new emerging moths compared to the control. Consecutive sprays of these extracts against eggs, larvae and pupae on same treated plants lead to very low number of moths for a second generation of the pest which contributes to low buildup of pest population in a tomato crop.
\end{abstract}

Key words: Tuta, leafminer, tomato, Melia, plant extract, indigenous species.

\section{Introduction}

The tomato leafminer, Tuta absoluta (Meyriek) (Lepidoptera: Gelechiidae) is one of the important lepidopteran pests associated with tomato production [1]. This leafminer is a key economic pest in the Middle East and the Mediterranean basin [2]. It is an oligophagous pest of outdoor and greenhouse tomatoes and it also attacks other Solanaceae crops [3]. The caterpillar is the most destructive stage of the pest, which mines voraciously in tomato leaves, and also damage flowers, fruits and stems [4]. Chemical

Corresponding author: Efat Abou-Fakhr Hammad, Ph.D., research fields: applied entomology, botanical pesticides. control using synthetic insecticides was the primary method of control for Tuta sp. [5], but these chemicals have reduced profits due to high insecticide costs, destruction of natural enemy populations [6], buildup of insecticide residues on tomato fruits [7] and basically the development of insecticide resistance to the leafminer pest $[8,9]$. Thus, in order to avoid selection of resistant pest biotypes, a careful management with frequent changes of active ingredients is desirable; as use of botanical products that have proven to be as potent as many conventional synthetic pesticides and also possess great advantage over synthetic pesticides in being more environment friendly in different agro-ecosystems and being 
readily acceptable by organic farmers, governmental organizations and others.

Many plants may be cultivated to provide sources of biodegradable pesticides [10]. The chinaberry tree, Melia azedarach L. (Sapindales: Meliaceae), is a deciduous tree often grown for its medicinal uses and for shade or ornament on roadsides. The non-conventional pesticidal effects of extracts or compounds isolated from Meliaceae trees against various pests include: partial reduction or complete inhibition of fecundity and egg hatchability, reduction of life span of adult pests, oviposition deterrence, antifeedant effects, and growth regulatory effects at molting of arthropods [11].

A few studies have dealt with use of Meliaceae plants or their components as potential pesticides against tomato leafminer. Neem-based products of high azadirachtin content caused high mortality of this insect, egg-laying avoidance and affected walking by larvae, but not leaf-mining of the pest [12]. These results indicated the potential of azadirachtin, as an insecticide important for organic farming, in the form of an egg-laying deterrent minimizing $T$. absoluta infestation and may also favor escape by larvae to exposure as it initiated behavioral avoidance. Da Cuncha et al. [13] identified fractions of aqueous and organic extracts of the meliaceous Trichilia pallens with insecticidal activity against the tomato leafminer. They found that $0.1 \%$ of the aqueous fraction, obtained from the partition assay of dichloromethane extracts, showed the highest insecticidal activity against $T$. absoluta larvae. Other plant extracts having insecticidal, antifeedant and repellent compounds were also investigated as potential agents for $T$. absoluta control [14]. The objective of the current work was to study the direct and indirect effects of aqueous and non-aqueous fruit extracts of indigenous M. azedarach, crushed fruits and powder formulations, in comparison to selected biorational products against the adult and immature instars of the tomato leafminer; to be incorporated as a practical control measure in organic farming agro-ecosystems.

\section{Materials and Methods}

Experiments were conducted at the Department of Plant Protection, Faculty of Agriculture and Veterinary Sciences, Lebanese University, Dekwaneh, Lebanon under controlled laboratory conditions of $26.16 \pm 1.54{ }^{\circ} \mathrm{C}, 60.21 \% \pm 4.49 \% \mathrm{RH}$ and $14: 10$ (light:dark) photoperiod.

\subsection{Plant Source and Supply}

Seeds of tomato, Lycopersicon esculentum L., Ace 55 Vf (ALH overseas SAL; Yammin Co. Dekwaneh, Lebanon) were used in the insect rearing colony and during all the experiments. Two-true leaf seedlings, from germinated tomato seeds, were grown in insect proof wooden cages $(95 \mathrm{~cm} \times 95 \mathrm{~cm} \times 135 \mathrm{~cm})$ covered with mesh $(100 \mu \mathrm{m})$. Seedlings were drenched with fungicide Macolazyl ${ }^{\circledR}$ and were supplied with NPK (12-12-12) water soluble fertilizer, once a week, to keep the plants healthy through the period of the experiments.

\subsection{Insect Rearing}

The leafminer colony was raised under laboratory conditions of $26.33 \pm 0.79{ }^{\circ} \mathrm{C}$ and $63.95 \% \pm 4.49 \%$ $\mathrm{RH}$. The colony, originally from infested field tomato leaves with leafminer larvae, was reared on tomato plants of the variety mentioned above in insect proof cages. The emerging adult moths of $T$. absoluta from the infested leaves were collected by a manual aspirator (Hausherrs Machine Works, USA) and were introduced into another insect proof cage full of healthy tomato plants, labeled as stock insect rearing cage. In preparation for the experiments, 2-true leaf tomato seedlings were introduced into the latter rearing cage; after $4 \mathrm{~d}$ of plants exposure to adult moths, all plants were moved to another insect proof cage. These transferred plants should have eggs of $T$. absoluta that are all approximately of the same age (3-4 d); adults emerging after about $15 \mathrm{~d}$ in this last 
cage were used in the experiments, as these moths were of similar age.

\subsection{Preparation of M. azedarach Extracts}

\subsubsection{Plant Materials}

Fruits of $M$. azedarach were collected at the green stage (about chickpea seed size) and at the mature yellowish stage (chickpea seed size) on June, 2014 and September 2015 from trees located in Mreyje and Jouniyeh, Mount Lebanon; for the adult instar experiment and the immature instars experiments, respectively. Fruits were stored at $-20{ }^{\circ} \mathrm{C}$; when needed the frozen fruits were washed with distilled water, air dried at ambient temperature before extraction.

\subsubsection{Extraction of Plant Materials}

M. azedarach fruits were crushed and extracted with different solvents: distilled water, methanol and ethyl acetate at a rate of 1:2 and/or 1:5 equivalent weight per volume (w:v), i.e., 500,000 ppm and 200,000 ppm, respectively. For the immature instars, larvae and pupae, fruits were freeze dried at 0.25 mBar and $-15{ }^{\circ} \mathrm{C}$ for about $4 \mathrm{~d}$ and then pulverized into fine powder $(30-40 \mu \mathrm{m})$. M. azedarach powder (MP) was extracted in different solvents: water, methanol, ethanol, ethyl acetate, hexane and chloroform at a rate of 1:500 (w:v), i.e., 2,000 ppm. Crushed fruits and MP were soaked for $24 \mathrm{~h}$ and then filtered using a sterile fine mesh $(50 \mu \mathrm{m})$. The organic solvents in filtrates of extracts were removed by a rotary evaporator. The deposited plant materials of each extract were re-dissolved in distilled water to be applied on tomato plants in the experiments.

\subsection{Experimental Set-Up}

The bioassays were executed in single plant cages. Each tomato plant ( $20 \mathrm{~d}$ old) was placed in a plastic cylindrical cage $(30 \mathrm{~cm} \times 20 \mathrm{~cm}$ height by diam.) with three perforated holes $(5 \mathrm{~cm}$ in diam.) on the sides of the cage; these holes and the ceiling of the cage were covered with a mesh $(100 \mu \mathrm{m})$ to allow ventilation.
Non-infested/infested plant with specific leafminer instar was sprayed by each treatment (about 10 $\mathrm{mL} /$ plant) till run-off, covering the upper and lower sides of the leaves using a glass bottle sprayer (50 $\mathrm{mL}$ ). Each treated seedling was allowed to air dry and then placed in a cage for consequent observations and data collection.

\subsubsection{Leafminer Adult Instar}

Six treatments were assayed against the adults of $T$. absoluta in plant cages. Treatments included: $M$. azedarach crushed fruit aqueous extracts 1:5 and 1:2 $(\mathrm{w}: \mathrm{v})$; the three commercial bio-rational pesticides, NeemAzal $^{\circledR} \quad \mathrm{T} / \mathrm{S}$ (1\% Azadirachtin A; Trifolio-M GmbH Co., Germany), petroleum oil 98\% (w/w) EC Damoil $^{\circledR}$ (Drexel Chemical Company, U.S.A), and micronized sulfur $80 \%(\mathrm{w} / \mathrm{w})$ Sufrox $^{\circledR}$ (Asmida, Lebanon) applied at the rate of $0.2 \mathrm{~mL}, 0.2 \mathrm{~mL}$, and $0.1 \mathrm{~g} / 100 \mathrm{~mL}$, respectively, and control, distilled water. Three adult unsexed moths of 3-4 d old were released on one treated plant inside a cage; the moths were observed for their location on one of the following parts of the cage: ceiling, floor, pot, plant, soil and sides of the cage; observations were recorded at 24, 48 and $72 \mathrm{~h}$. The released moths were removed from the cage after $72 \mathrm{~h}$ and observations on consequent immature instars were recorded daily till the end of the experiment. Live and dead insect instars were inspected at $40 \times$ magnification.

\subsubsection{Leafminer Immature Instars}

Bioassays related to leafminer immatures: eggs, larvae and pupae were executed in separate experiments to study the direct effect of plant extracts on the leafminer immatures. Three adult unsexed moths of 3-4 d old were released on un-treated plant in a single plant cage at the initiation of each experiment; the released adult moths were removed from the cage at $72 \mathrm{~h}$. Then, the infested plant was treated at the appropriate instar to be studied and placed in its corresponding cage.

\subsubsection{Egg Instar}

The initial number of eggs laid on plant by the 
three released moths was counted after $72 \mathrm{~h}$ of release in cage. The infested plants by T. absoluta eggs were sprayed by 11 treatments including M. azedarach fruit extracts (MFE) in water, methanol, and ethyl acetate 1:5 (w:v) with and without mineral oil (2\%), the three commercial biorational pesticides mentioned above, thyme oil (extracted from local Lebanese thyme) and control, distilled water. It is important to note that thyme oil had caused phytotoxicity on tomato plants at concentrations of $2 \%, 1 \%$ and $0.5 \%$; so it was tested at the rate of $0.2 \%(2,000 \mathrm{ppm})$. The numbers of live and dead eggs in form of dry, deformed and oozing eggs were recorded at 24, 48 and $72 \mathrm{~h}$ after treatments. Consequently, the live and dead larval instars (L1, L2 and L3) and pupae were counted daily in all treatments till emergence of new adult moths; healthy tomato plants were introduced into the cage to allow live larvae to continue their growth, as needed.

\subsubsection{Larval Instars}

Initial number of early larval instars (L1 and L2) was recorded $3 \mathrm{~d}$ after removal of the released moths. Larvae were sprayed with 18 treatments including: eight MP extracts 1:500 (w:v), M. azedarach fruit aqueous extracts $1: 5$ and 1:2 (w:v); NeemAzal ${ }^{\circledR}$; control in form water, untreated control and organic solvents (10\%): methanol, ethanol, ethyl acetate, hexane and chloroform. Treated larvae were observed for 12 consecutive days to check for being dead or deformed or developing into dead or healthy pupae and consequently newly emerging adult moths.

\subsubsection{Pupa Instar}

Pupae were sprayed topically with 18 treatments as those tested against larval instars mentioned above, in glass Petri dishes. Treated pupae (three replicates, each replicate of three pupae) were observed for seven consecutive days to check for being dead or deformed pupae or developing into healthy or non-healthy adult moths.

\subsubsection{Consecutive Treatments}

Similar to above experiments related to immature instars, but here each treatment was applied at three consecutive instars of the leafminer on the same plant. The 1st spray was applied at the laid eggs, after removal of the released moths into the cage; the 2 nd spray was at the larval instars L1-L2 (8 d after egg laying) and the 3rd spray was at the pupal stage in Petri dishes (16 d after egg laying), consecutively. These immature instars were sprayed by 18 treatments mentioned above, as those tested directly against larval instars L1-L2 and pupae. Each insect was checked for being alive or dead according to the symptoms on eggs, larvae and pupae as described above.

\subsection{Statistical Analysis}

The experiments were laid out in a completely randomized block design with two factors: treatment and date of batch. Each treatment was repeated on three different dates, with each treatment replicated three times on each date. The collected data was analyzed using General Linear Model with two factors, treatment and observation date. The data was collected in the form of live or dead moths, eggs, larvae and pupae per plant. The average numbers of each instar were used in the data analysis after ensuring their normal distribution by transforming the data using sqrt $(x+1) ; x$ being the number or $\%$ of live or dead moths, larvae, pupae and newly emerging adults per plant, to normalize the data distribution. Means were used in analysis of data and were separated by Student-Newman-Keuls test if significant $F$ values were obtained, at $0.05 \%$ level of significance, using the SPSS statistical package [15].

\section{Results and Discussion}

Data analysis have revealed consistent efficacy in decreasing encountered number of adults and immatures of the tomato leafminer in treatments with plant extracts and other biorational products under laboratory conditions. 
3.1 Effects of $M$. azedarach Extracts and Selected Biorational Pesticides on the Tomato Leafminer Adult Instar

There was significant difference in \% live moths on plant among treatments $(F=2.652$; df $=5(157) ; p=$ $0.025)$ and among observations $(F=4.480 ; \mathrm{df}=2$ (157); $p=0.013$ ), but there was no significant interaction among treatments and observations at 24 , 48 or $72 \mathrm{~h}$. The micronized sulfur treatment allowed the lowest number of live moths to be present on treated plant inside the cage; this treatment was comparable in its effect to M. azedarach extracts and the oils, but the latter treatments were comparable in their effect to that of the control, distilled water (Table 1). Thus, sulfur can act as repellent against T. absoluta moths. Furthermore, the number of live adult moths on tomato plants was highest at $24 \mathrm{~h}$ after treatment, but was lowest at $48 \mathrm{~h}$ in all treatments, except neem oil. Thus, observations at $24 \mathrm{~h}$ indicated that there was no toxic effect of treatments on Tuta adults. However, observations at $72 \mathrm{~h}$ confirmed the repellent efficacy of tested products; the lowest number of moths being detected on plants treated with sulfur followed by $M$. azedarach extracts and neem oil. On the contrary, Zappala et al. [16] found that dustable sulphur significantly reduced the infestation of T. absoluta and had a repellent effect on oviposition, but wettable sulphur was not effective for controlling the leafminer populations in both greenhouse and open-field experiments. However, in their side effect trials with the Hemipteran predator Nesidiocoris tenuis (Reuter), only dustable sulphur resulted in being moderately harmful as a fresh residue and slightly harmful as a 7-day-old residue; whereas, wettable sulphur was classified as harmless to $N$. tenuis. Thus, sulfur in both formulations, powder and micronized wettable, could be considered as a tool in $T$. absoluta management strategies, although its possible side effects on $N$. tenuis should be taken into account.

Knowing that botanical products are generally characterized by reduced stability with the presence of a pest on treated plants was more obvious with time [17], mostly with non-repellent products. Furthermore, there was no significant difference in \% dead moths encountered among all treatments and the control (Table 1); this indicates that there was no direct toxicity effect of treatments against the adult moths and that the detected mortality was comparable to that of the control that usually corresponds to natural mortality of the insect. In addition, there was no significant difference in number of live moths, encountered on different parts of the cage as ceiling, sides and floor of cage and even on soil and pot inside the cage, among all treatments including the control. Thus, the experimental set up of this study was satisfactory and did not interfere with survival of the moths. Hence, M. azedarach extracts and the tested products are not toxic to the adult tomato leafminer, but have potential repellent effect of $73.34 \%-78.68 \%$ and of $76.62 \%-87.69 \%$ moths live inside cage (not on treated plant), respectively, versus that of the control of $67.87 \%$ (Table 1 ).

Furthermore, results of this experiment indicated that there was no significant difference in number of live 1st larval instar (L1) of T. absoluta, hatching from laid eggs by moths on treated plants, among treatments. However, there was significant difference in number of live 2nd larval instar (L2) $(F=2.323$; df $=5(215) ; p=0.044)$ and 3rd larval instar (L3) $(F=$ 7.015; df $=5$ (215); $p<0.05)$ among treatments (Table 2). Sulfur seems to cause the lowest numerical number of larvae (L2) to be encountered on tomato plants and was comparable to other treatments, except M. azedarach fruit extract in water (MFE-W2) which was comparable to the control. However, all treatments caused a significant decrease in number of 3rd larval instars compared to the control in the following order: sulfur, neem oil, MFE-W1, mineral oil and MFE-W2. The sulfur effect might be related to encountering the lowest number of adult moths per plant compared to the control at the beginning of the experiment. However, the botanical products seem to 
Table 1 Effect of Meliaa zedarach extracts and selected biorational products against Tuta absoluta moths on treated tomato plants under laboratory conditions.

\begin{tabular}{llll}
\hline Treatment* & \% Live moths on treated plant & \% Dead moths in cage*** & \% Live moths in cage**** \\
\hline Micronized sulfur & $8.64 \pm 11.26 \mathrm{~b}^{* *}$ & $3.67 \pm 0.60$ & 87.69 \\
MFE-W1 & $11.99 \pm 7.85 \mathrm{ab}$ & $9.33 \pm 1.10$ & 78.68 \\
Neem oil & $19.75 \pm 7.40 \mathrm{ab}$ & $1.33 \pm 0.30$ & 78.92 \\
MFE-W2 & $15.99 \pm 10.31 \mathrm{ab}$ & $10.67 \pm 1.11$ & 73.34 \\
Mineral oil & $16.05 \pm 6.67 \mathrm{ab}$ & $7.33 \pm 0.90$ & 76.62 \\
Control & $23.46 \pm 8.68 \mathrm{a}$ & $8.67 \pm 1.8$ & 67.87 \\
\hline
\end{tabular}

Values represent mean $\pm \mathrm{SE}$.

* $\mathrm{MFE}=$ M. azedarach fruit extract; $\mathrm{W}=$ water; equivalent concentrations: $1=500,000$ ppm, i.e., 1:2 (w:v); $2=200,000$ ppm, i.e., 1:5 (w:v); control = distilled water.

** Means within a column followed by the same letter are not significantly different.

*** There was no significant difference in number of dead moths among all treatments.

$* * * *$ Value $=100-(\%$ live moths on treated plant $+\%$ dead moths in cage $)$.

Table 2 Effect of $M$. azedarach fruit extracts and selected biorational pesticides on larvae of $T$. absoluta, emerging from laid eggs by moths on treated plants, under laboratory conditions.

\begin{tabular}{lllll}
\hline \multirow{2}{*}{ Treatment* } & \multicolumn{3}{c}{ Number of live larvae per plant } & No. of dead larvae/plant** \\
\cline { 2 - 5 } & L1** & L2 & L3 & $0.26 \pm 0.08$ \\
\hline WControl & $5.14 \pm 1.91$ & $4.06 \pm 1.21 \mathrm{ab} * * *$ & $6.72 \pm 1.83 \mathrm{a}$ & $0.22 \pm 0.09$ \\
Mineral oil & $2.28 \pm 1.16$ & $2.03 \pm 0.76 \mathrm{ab}$ & $2.75 \pm 0.76 \mathrm{~b}$ & $0.04 \pm 0.03$ \\
Neem oil & $6.44 \pm 2.02$ & $2.03 \pm 0.67 \mathrm{ab}$ & $0.61 \pm 0.32 \mathrm{~b}$ & $0.11 \pm 0.06$ \\
Micronized sulfur & $2.23 \pm 1.79$ & $0.89 \pm 0.62 \mathrm{a}$ & $0.36 \pm 0.14 \mathrm{~b}$ & $0.32 \pm 0.11$ \\
MFE-W2 & $6.19 \pm 2.28$ & $6.50 \pm 2.25 \mathrm{~b}$ & $3.78 \pm 1.18 \mathrm{~b}$ & $0.28 \pm 0.10$ \\
MFE-W1 & $3.31 \pm 1.12$ & $2.44 \pm 0.95 \mathrm{ab}$ & $0.89 \pm 0.40 \mathrm{~b}$ &
\end{tabular}

Values represent mean $\pm \mathrm{SE}$.

* $\mathrm{MFE}=$ M. azedarach fruit extract; $\mathrm{W}=$ water; equivalent concentrations: $1=500,000$ ppm, i.e., 1:2 (w:v); $2=200,000$ ppm, i.e., 1:5 (w:v); control = distilled water.

** There was no significant difference in number of larvae per plant among all treatments.

*** Means within a column followed by the same letter are not significantly different.

have a delayed effect on immatures of the leafminer, represented by low number of the 3rd instar larvae, which can be described in the form of insect growth regulatory effect, but non-toxic effect as number of dead larvae was not significantly different among all treatments and the control (Table 2). Furthermore, it is important to note that larvae on treated plants with $M$. azedarach extracts had abnormal growth symptoms, whereas neem oil caused smaller mines, which indicates that neem oil might have an antifeedant effect which forces early larval instars to stop feeding in their mines. However, the mineral oil symptom through both physical contact toxicity and suffocation was unlike that of $M$. azedarach extracts and neem oil which can be described simply as brown dead larvae in their mines.

\subsection{Effects of M. azedarach Extracts and Selected Biorational Products on the Tomato Leafminer Immatures}

\subsubsection{Egg Instar}

\subsubsection{Oviposition Capacity of the Adult Leafminer}

Under the laboratory conditions of this study, it was found that the average number of eggs laid per one female moth of T. absoluta is 42 eggs in $3 \mathrm{~d}$ and the ratio of adult female to male moths was 1:2. Thus, one female moth would lay 117-175.5 eggs in its life time under conditions of these experiments, knowing that the female moth lives for 10-15 $\mathrm{d}$ [18] and that one moth can lay about 260 eggs during its lifetime [1]. 


\subsubsection{Direct Effects on the Leafminer Eggs}

Results of this experiment indicated that there was significant difference in \% dead eggs of $T$. absoluta $(F=45.023 ; \mathrm{df}=10(1,286) ; p<0.05)$ among treatments. Specifically, there was significant difference in $\%$ dry $(F=43.043 ; \mathrm{df}=10(1,286) ; p<$ $0.05), \%$ deformed $(F=12.323 ; \mathrm{df}=10(1,286) ; p<$ $0.05)$, and $\%$ oozing eggs $(F=20.077 ; \mathrm{df}=10$ $(1,286) ; p<0.05)$ among treatments (Table 3$)$, and it seems that the dry effect on eggs contributed mostly to the number of dead eggs. M. azedarach fruit extract in ethyl acetate (MFE-EA2) and MFE-W2 + oil seems to cause the highest \% of dead and dry eggs of $41.77 \%, 41.12 \%, 40.98 \%$ and $39.29 \%$, respectively, followed by MFE-EA2 + oil, $M$. azedarach fruit extract in methanol (MFE-MOH2) + oil, neem oil, MFE-W2, MFE-MOH2, sulfur, mineral oil and thyme oil. Thus, all treatments were comparable in the dry effect to that of neem oil, except for MFE-EA2 and thyme oil which caused significant higher and lower dry effect than neem oil, respectively, knowing that MFE and the latter oil have different wt. equivalent concentrations of $200,000 \mathrm{ppm}$ and 2,000 ppm, respectively. It seems also that ethyl acetate is extracting more or different bioactive chemicals, effective against Tuta eggs, compared to other solvents. These results also indicated that mineral oil seems to increase the activity of MFE against the eggs of T. absoluta in terms of numerical increase of dead eggs. Furthermore, all treatments caused dry effect on eggs of the leafminer, but only some treatments caused deformation and oozing symptoms on the insect eggs in the range of $0.02 \%-0.52 \%$ and $0.11 \%-1.68 \%$, respectively.

On the other hand, results of this experiment indicated that there was significant increase in $\%$ dead eggs and $\%$ dry eggs $(F=14.713 ; \mathrm{df}=12(1,286) ; p<$ 0.05 and $F=14.355 ;$ df $=12(1,286) ; p<0.05$, respectively) through observations. The dry eggs symptoms started at $24 \mathrm{~h}$ after treatment and continued to increase to reach the maximum number at observation six which confirmed the direct dry effect of treatments against insect eggs. However, there was no significant difference in $\%$ oozing and deformed eggs through observations, but these symptoms were observed starting at $24 \mathrm{~h}$ and $48 \mathrm{~h}$ after treatment, respectively.

A few studies dealt with direct effect of botanical products against insect eggs. The harmful effect of

Table 3 Direct effects of $M$. azedarach extracts and selected biorational products on laid eggs of T. absoluta under laboratory conditions.

\begin{tabular}{lll}
\hline Treatment* & \% Dead eggs**/plant & \% Dry eggs/plant \\
\hline MFE-EA2 & $41.77 \pm 2.17 \mathrm{a}^{* * *}$ & $41.12 \pm 2.18 \mathrm{a}$ \\
MFE-W2 + mineral oil (2\%) & $40.98 \pm 2.25 \mathrm{a}$ & $39.29 \pm 2.37 \mathrm{ab}$ \\
MFE-EA2 + mineral oil (2\%) & $39.29 \pm 3.05 \mathrm{ab}$ & $38.85 \pm 3.07 \mathrm{ab}$ \\
MFE-MOH2 + mineral oil (2\%) & $37.69 \pm 2.24 \mathrm{ab}$ & $37.56 \pm 2.23 \mathrm{ab}$ \\
Neem oil (2\%) & $32.59 \pm 2.20 \mathrm{bc}$ & $32.59 \pm 2.20 \mathrm{bc}$ \\
MFE-W2 & $31.91 \pm 1.86 \mathrm{bc}$ & $31.39 \pm 1.90 \mathrm{bcd}$ \\
MFE-MOH2 & $29.11 \pm 2.36 \mathrm{~cd}$ & $29.11 \pm 2.36 \mathrm{~cd}$ \\
Micronized sulfur & $27.81 \pm 2.10 \mathrm{~cd}$ & $27.31 \pm 2.09 \mathrm{~cd}$ \\
Mineral oil (2\%) & $24.81 \pm 2.51 \mathrm{~cd}$ & $24.38 \pm 2.51 \mathrm{~cd}$ \\
Thyme oil $(0.2 \%)$ & $23.19 \pm 1.39 \mathrm{~d}$ & $23.19 \pm 1.39 \mathrm{~d}$ \\
WControl & $0.00 \pm 0.00 \mathrm{e}$ & $0.00 \pm 0.00 \mathrm{e}$
\end{tabular}

Values represent mean $\pm \mathrm{SE}$.

$* \mathrm{MFE}=$ M. azedarach fruit extract; solvents: $\mathrm{EA}=$ ethyl acetate, $\mathrm{MOH}=$ methanol, $\mathrm{W}=$ water; concentration: $2=200,000$ ppm, i.e., 1:5 (w:v); WControl = water control.

** Dead eggs are total dead eggs in form of dry, deformed and oozing symptoms.

*** Means within a column followed by the same letter are not significantly different. 
neem was observed in the low hatching of caterpillars from egg masses of the cabbage moth Mamestra brassicae [19]. Tavares et al. [20] also tested the activity of neem on egg masses of different ages of the fall armyworm noctuid Spodoptera frugiperda (J.E. Smith) and the pyralid sugarcane borer Diatraea saccharalis (Fabricius). They found that with $1 \%$ and $2 \%$ neem extracts, hatching of $S$. frugiperda larvae from recently laid eggs, one-day and two-day old eggs was $7.50 \%, 6.2 \%, 13.7 \%, 7.50 \%, 15.00 \%$ and $7.50 \%$, respectively. However, hatching of $D$. saccharalis larvae from different age eggs was $0.00 \%$ with those neem extracts. Thus, the high hatching of $S$. frugiperda eggs with the $1 \%$ neem extract seems to suggest a greater resistance of this pest to natural products; this increase in hatching with age of eggs is due to the hardening of the egg shell with time that ensures protection to the embryo of the insect. Similarly, in this study the \% hatching eggs of $T$. absoluta treated with plant extracts was relatively high in the range of $12.34 \%-16.92 \%$ as the eggs were of 1-3 d old (Table 3).

3.2.1.3 Indirect Effects on Larvae Hatching from Treated Leafminer Eggs

Results of this experiment indicated that there were significant indirect effects against larvae of $T$. absoluta that hatched from treated eggs with $M$. azedarach extracts and biorational products. There were significant differences in numbers of $T$. absoluta live $\mathrm{L} 1(F=4.906 ; \mathrm{df}=10(1,286) ; p<0.05), \mathrm{L} 2(F=$ $10.730 ; \mathrm{df}=10(1,286) ; p<0.05)$ and $\mathrm{L} 3(F=42.601$; $\mathrm{df}=10(1,286) ; p<0.05)$ among treatments (Table 4$)$. However, all treatments were not significantly different in number of live L1 from that of the control, but all treatments were significantly different in number of live L2 and L3 from the control. Neem oil (2\%) seems to cause the lowest number of live L2 and L3 followed in an increasing order by MFE-MOH2 + oil, MFE-W2 + oil, MFE-EA2 + oil, mineral oil, sulfur and other M. azedarach extracts. On the other hand, there was significant difference $(F=29.285$; df $=10(1,286) ; p<0.05)$ in $\%$ dead larvae among treatments and the control (Table 4). Thyme oil caused the highest larval mortality of $25.85 \%$ and was significantly different in its effect from all other treatments. M. azedarach extract MFE-W2 and micronized sulfur were not significantly different in their effect on larvae from neem oil causing $21.34 \%$, $21.01 \%$ and $23.34 \%$, respectively. The latter oil was comparable in its effect to that of mineral oil that caused

Table 4 Indirect effect of M. azedarach extracts and biorational products on larvae (L1, L2, L3) of T. absoluta that hatched from treated eggs under laboratory conditions.

\begin{tabular}{lllll}
\hline \multirow{2}{*}{ Treatment* } & \multicolumn{3}{c}{ Number of live larvae per plant } & \% Dead larvae/plant \\
\cline { 2 - 5 } & Live L1 & Live L2 & Live L3 & $23.34 \pm 1.29 \mathrm{bc}$ \\
Neem oil (2\%) & $10.53 \pm 1.38 \mathrm{a}^{* *}$ & $1.34 \pm 0.48 \mathrm{e}$ & $0.38 \pm 0.09 \mathrm{f}$ & $18.08 \pm 1.23 \mathrm{~cd}$ \\
Mineral oil (2\%) & $9.25 \pm 1.23 \mathrm{ab}$ & $3.15 \pm 0.17 \mathrm{bcd}$ & $1.92 \pm 0.35 \mathrm{cde}$ & $21.34 \pm 1.24 \mathrm{~b}$ \\
MFE-W2 & $9.16 \pm 1.27 \mathrm{abc}$ & $4.12 \pm 0.62 \mathrm{bc}$ & $2.93 \pm 0.50 \mathrm{bc}$ & $2.39 \pm 1.30 \mathrm{f}$ \\
Control & $7.54 \pm 0.98 \mathrm{abcd}$ & $7.10 \pm 0.59 \mathrm{a}$ & $9.86 \pm 1.09 \mathrm{a}$ & $17.70 \pm 1.28 \mathrm{de}$ \\
MFE-MOH2 + oil & $7.36 \pm 0.93 \mathrm{abcd}$ & $2.42 \pm 0.64 \mathrm{~d}$ & $1.56 \pm 0.28 \mathrm{cde}$ & $17.49 \pm 1.22 \mathrm{e}$ \\
MFE-EA2 + oil & $7.25 \pm 1.13 \mathrm{bcd}$ & $4.14 \pm 0.28 \mathrm{bcd}$ & $1.53 \pm 0.30 \mathrm{de}$ & $21.01 \pm 1.22 \mathrm{bc}$ \\
Micronized sulfur & $7.12 \pm 1.07 \mathrm{bcd}$ & $4.03 \pm 0.53 \mathrm{bc}$ & $3.09 \pm 0.44 \mathrm{~b}$ & $16.16 \pm 1.27 \mathrm{de}$ \\
MFE-MOH2 & $6.17 \pm 0.75 \mathrm{bcd}$ & $4.59 \pm 0.54 \mathrm{~b}$ & $3.52 \pm 0.55 \mathrm{~b}$ & $14.86 \pm 1.31 \mathrm{de}$ \\
MFE-EA2 & $5.19 \pm 0.68 \mathrm{bc}$ & $3.93 \pm 0.36 \mathrm{bc}$ & $2.13 \pm 0.32 \mathrm{bcd}$ & $25.85 \pm 1.21 \mathrm{a}$ \\
Thyme oil $(0.2 \%)$ & $5.00 \pm 0.7 \mathrm{~d}$ & $3.72 \pm 0.52 \mathrm{bcd}$ & $2.67 \pm 0.38 \mathrm{bc}$ & $15.01 \pm 1.23 \mathrm{de}$ \\
MFE-water + oil & $4.61 \pm 0.60 \mathrm{~d}$ & $2.51 \pm 0.51 \mathrm{~cd}$ & $0.89 \pm 0.15 \mathrm{ef}$ & \\
\hline
\end{tabular}

Values represent mean $\pm \mathrm{SE}$.

* $\mathrm{MFE}=$ M. azedarach fruit extract; solvents: $\mathrm{EA}=$ ethyl acetate, $\mathrm{MOH}=$ methanol, $\mathrm{W}=$ water; concentrations: $2=200,000 \mathrm{ppm}$ i.e., 1:5 (w:v); WControl = water control.

** Means within a column followed by the same letter are not significantly different. 
18.08\% mortality. All M. azedarach extracts, except MFE-W2, were comparable in their effects to that of mineral oil causing larval mortality of $14.86 \%-17.70 \%$.

Thyme oil seems to be a feeding deterrent to early larval instars hatching from treated eggs with this oil as numbers of live L1, L2 and L3 were lowest among treatments and consequently showed highest larval mortality (Table 4). Similarly, Kordan et al. [21] found that thyme and its terpenoid constituent thymol to be potentially feeding deterrent to Cameraria ohridella Deschka and Dimić (Lepidoptera: Gracillariidae) larvae and the latter compound was recommended as a supplementary behavior-controlling allelochemical.

On the other hand, M. azedarach extracts have caused larval death due to their systemic mode of action which might have caused the larvae to stop feeding on leaves and consequently retarded their growth or might have led to their death due to starvation; a similar mode of action to that of neem oil. More specifically, MFE were noticed to cause deformation to the larvae mainly on the abdominal part and the dead larvae seems to be deformed, shrunk and dry in their mines. On the other hand, the effect of $M$. azedarach extracts and the biorational products caused a significant increase in \% dead larvae $(F=$ 39.705; df $=12(1,286) ; p<0.05)$ on treated plants among observations starting at $48 \mathrm{~h}$ after treatment reaching the maximum mortality of $44.11 \%$ at $13 \mathrm{~d}$ after treatment, knowing that \% dead larvae in the control was only $2.39 \%$ through the experiment (Table 4).

\subsubsection{Indirect Effects on Pupae Developing from} Treated Leafminer Eggs

Results of this experiment indicated that there was significant difference in $\%$ live pupae among treatments $(F=61.786$; df $=10(1,286) ; p<0.05)$. The $M$. azedarach extracts and the tested biorational products allowed encountering significantly less number of pupae from that of the control,
$0.04 \%-0.83 \%, 0.13 \%-1.47 \%$ and $9.82 \%$, respectively. This indicates that the extracts and the tested products have indirect effect on pupation as they interrupt the insect life cycle and will sequentially lead to a lower population of this pest. Consequently, there was significant difference in \% new adult moths emerging from live pupae among treatments $(F=62.373$; df $=$ $10(1,286) ; p<0.05) ; \%$ emerging moths in the treatments with plant extracts, biorational products and the control were $0.14 \%-0.89 \%, 0.08 \%-1.23 \%$ and $9.37 \%$, respectively.

Several studies have dealt with botanical extracts against the tomato leafminer [5, 22-25]. The penetration and action of neem compounds caused a higher mortality rate at the cellular level of insects with interference in the growth regulation hormones, metamorphosis and insects reproduction. Kona et al. [26] studied the effect of botanical extracts of neem (A. indica) and Jatropha (Jatropha curcus L.) on eggs of T. absoluta in the laboratory. Hundred grams of each plant powder were used; extraction of neem was with ethanol and that of Jatropha was with petroleum ether. In the tests, five concentrations $(1,000,500,250,125$ and $62.5 \mathrm{mg} / \mathrm{L})$ were prepared from the stock solutions. Five groups of 40-50 eggs of $T$. absoluta were topically treated with the different concentrations of each extract in Petri dishes. Results of this study indicated that after $4 \mathrm{~d}$ of applying the extracts, about $24 \%-26 \%$ and $18 \%-25 \%$ egg mortality was observed due to neem and Jatropha seed extracts, respectively. Similarly, in the current study, the effects of MFE were revealed directly on the egg instar of the tomato leafminer in the form of significantly high \% of dead eggs of $29.11 \%-41.77 \%$; knowing that these MFE are of a concentration of 200,000 ppm versus 1,000 ppm for neem seeds powder in the latter study. Effects of MFE were also revealed indirectly on the developing larvae causing larval mortality of $14.86 \%-21.34 \%$ and consequently leading to significantly low \% of developing pupae and newly 
emerging moths compared to the control at the end of this experiment.

\subsubsection{Larval Instars}

\subsubsection{Direct Effects on Larvae (L1 and L2)}

Results of this experiment indicated that there was significant direct effect on L1 and L2 larval instars. There was significant difference in \% L1 mortality $(F$ $=49.825 ; \mathrm{df}=17(1,943) ; p<0.05)$ among treatments and the controls, water and untreated (Table 5). The highest L1 mortality was caused by neem oil of $28.61 \%$ followed by MPE-W2, MPE-EA3, MPE-ethanol (MPE-EOH3), MPE-W1, MPE-hexane (MPE-H3), MPE-chloroform (MPE-C3) and MPE-W3 in the range of $24.11 \%-27.54 \%$. It is important to note that there was significant difference in \% dead L1 among MPE-EA3 and MPE-EOH3 and their corresponding solvents, but there was no significant difference among the other extracts and their corresponding organic solvents.

Specifically, there was significant difference in $\%$
L1 dry $(F=62.080 ; \mathrm{df}=17(1,943) ; p<0.05)$, brown $(F=17.172 ; \mathrm{df}=17(1,943) ; p<0.05)$, deformed $(F=$ 9.245; df $=17$ (1,943); $p<0.05)$, and shrunk $(F=$ 8.990; $\mathrm{df}=17(1,943) ; p<0.05)$ among treatments; all $M$. azedarach extracts were significantly different in their effects from the controls, water and untreated. The highest $\%$ dry L1 was caused by MPE-EA3 of $18.89 \%$ followed by MPE-W2, MPE-W1 and MPE-EOH3 causing $16.47 \%, 14.20 \%$ and $13.96 \%$, respectively; the latter three extracts were comparable to neem oil that caused $13.09 \%$ mortality (Table 6). However, only the former extract was significantly different in its effect from its corresponding organic solvent, EA-S10. The highest \% brown L1 was caused by neem oil of $13.53 \%$ followed by MPE-W3, MPE-W2, MPE-EOH3 and MPE-W1 causing 9.67\%-12.19\% mortality; all these extracts were significantly different in \% brown L1 from their corresponding solvents (Table 6). However, the deformed and shrink symptoms on L1 were very low

Table 5 Effects of $M$. azedarach extracts and neem oil on T. absoluta larvae under laboratory conditions.

\begin{tabular}{llll}
\hline Treatment* & \% Dead L1 & \% Dead L2 & \% Dead L3 \\
\hline UControl & $1.46 \pm 0.28 \mathrm{~g}^{* *}$ & $8.14 \pm 0.77 \mathrm{~d}$ & $10.44 \pm 1.16 \mathrm{~cd}$ \\
WControl & $5.21 \pm 0.75 \mathrm{f}$ & $9.56 \pm 0.84 \mathrm{~cd}$ & $8.31 \pm 0.90 \mathrm{~d}$ \\
MFE-W1 & $18.74 \pm 1.57 \mathrm{e}$ & $13.44 \pm 1.62 \mathrm{ab}$ & $15.13 \pm 2.00 \mathrm{ab}$ \\
EA-S10 & $15.63 \pm 0.74 \mathrm{de}$ & $15.22 \pm 0.97 \mathrm{ab}$ & $9.78 \pm 0.83 \mathrm{~cd}$ \\
MFE-W2 & $19.98 \pm 1.54 \mathrm{cde}$ & $18.34 \pm 2.06 \mathrm{a}$ & $10.32 \pm 1.48 \mathrm{~cd}$ \\
EOH-S10 & $18.59 \pm 0.90 \mathrm{cde}$ & $12.97 \pm 0.81 \mathrm{bc}$ & $12.01 \pm 1.06 \mathrm{bcd}$ \\
H-S10 & $18.57 \pm 0.85 \mathrm{bcde}$ & $14.97 \pm 0.91 \mathrm{ab}$ & $11.11 \pm 1.03 \mathrm{~cd}$ \\
MPE-MOH3 & $21.79 \pm 1.54 \mathrm{bcde}$ & $18.31 \pm 1.39 \mathrm{a}$ & $15.61 \pm 1.85 \mathrm{a}$ \\
C-S10 & $19.70 \pm 0.90 \mathrm{bcde}$ & $12.98 \pm 0.88 \mathrm{bc}$ & $10.99 \pm 1.03 \mathrm{~cd}$ \\
MOH-S10 & $19.89 \pm 0.89 \mathrm{bcd}$ & $15.67 \pm 0.96 \mathrm{ab}$ & $10.33 \pm 0.99 \mathrm{~cd}$ \\
MPE-W3 & $24.11 \pm 1.62 \mathrm{abc}$ & $17.22 \pm 2.07 \mathrm{ab}$ & $9.72 \pm 1.22 \mathrm{~cd}$ \\
MPE-C3 & $24.48 \pm 1.86 \mathrm{abc}$ & $17.87 \pm 1.77 \mathrm{ab}$ & $11.60 \pm 1.62 \mathrm{bcd}$ \\
MPE-H3 & $24.18 \pm 1.85 \mathrm{abc}$ & $16.47 \pm 1.76 \mathrm{ab}$ & $10.75 \pm 1.65 \mathrm{~cd}$ \\
MPE-W1 & $25.24 \pm 1.78 \mathrm{ab}$ & $16.97 \pm 1.57 \mathrm{ab}$ & $11.09 \pm 1.62 \mathrm{~cd}$ \\
MPE-EOH3 & $17.57 \pm 1.67 \mathrm{ab}$ & $12.33 \pm 1.46 \mathrm{abcd}$ \\
MPE-EA3 & $24.59 \pm 1.26 \mathrm{ab}$ & $16.12 \pm 1.76 \mathrm{ab}$ & $8.90 \pm 1.25 \mathrm{~d}$ \\
MPE-W2 & $26.78 \pm 1.69 \mathrm{ab}$ & $8.12 \pm 1.23 \mathrm{~d}$ & $13.82 \pm 2.05 \mathrm{abc}$ \\
Neem oil & $27.54 \pm 1.66 \mathrm{a}$ & $14.50 \pm 1.23 \mathrm{ab}$ & $9.14 \pm 1.56 \mathrm{~d}$
\end{tabular}

Values represent mean \pm SE.

$* \mathrm{MFE}=$ M. azedarach fruit extract; $\mathrm{MPE}=$. azedarach powder extract; $\mathrm{S} 10=$ solvent $(10 \%), \mathrm{C}=$ chloroform, $\mathrm{EOH}=\mathrm{ethanol}$, $\mathrm{EA}=$ ethyl acetate, $\mathrm{MOH}=$ methanol, $\mathrm{W}=$ water; concentrations: $1=500,000$ ppm, i.e., $1: 2(\mathrm{w}: \mathrm{v}), 2=200,000$ ppm, i.e., $1: 5$ (w:v), $3=2,000$ ppm, i.e., 1:500 (w:v); UControl = untreated control; WControl = water control.

** Means within a column followed by the same letter are not significantly different. 
Table 6 Specific effect symptoms of M. azedarach extracts on T. absoluta larvae under laboratory conditions.

\begin{tabular}{lllllll}
\hline Treatment* & \% Dry L1 & \% Brown L1 & \% Dry L2 & \% Brown L2 & \% Dry L3 & \% Brown L3 \\
\hline UControl & $0.00 \pm 0.00 \mathrm{f} *$ & $1.46 \pm 0.28 \mathrm{~h}$ & $4.47 \pm 0.46 \mathrm{e}$ & $3.67 \pm 0.38 \mathrm{e}$ & $6.74 \pm 0.78 \mathrm{a}$ & $3.69 \pm 0.49 \mathrm{cde}$ \\
WControl & $0.00 \pm 0.00 \mathrm{f}$ & $5.21 \pm 0.75 \mathrm{~g}$ & $4.79 \pm 0.52 \mathrm{de}$ & $4.77 \pm 0.43 \mathrm{de}$ & $7.02 \pm 0.73 \mathrm{a}$ & $1.29 \pm 0.29 \mathrm{f}$ \\
MFE-W1 & $9.93 \pm 0.89 \mathrm{e}$ & $8.25 \pm 0.75 \mathrm{cdef}$ & $4.94 \pm 0.74 \mathrm{de}$ & $8.30 \pm 0.97 \mathrm{ab}$ & $5.69 \pm 0.96 \mathrm{~b}$ & $8.67 \pm 1.09 \mathrm{a}$ \\
MFE-W2 & $10.87 \pm 0.80 \mathrm{de}$ & $9.11 \pm 0.83 \mathrm{bcde}$ & $7.79 \pm 1.07 \mathrm{bc}$ & $9.54 \pm 1.12 \mathrm{a}$ & $2.47 \pm 0.55 \mathrm{~cd}$ & $7.85 \pm 1.05 \mathrm{ab}$ \\
MPE-C3 & $12.45 \pm 1.18 \mathrm{cde}$ & $10.13 \pm 0.82 \mathrm{bcd}$ & $8.97 \pm 0.91 \mathrm{abc}$ & $6.67 \pm 0.74 \mathrm{bcd}$ & $4.09 \pm 0.80 \mathrm{bcd}$ & $7.13 \pm 0.90 \mathrm{ab}$ \\
EA-S10 & $10.56 \pm 0.61 \mathrm{cde}$ & $5.07 \pm 0.43 \mathrm{fg}$ & $10.36 \pm 0.65 \mathrm{abc}$ & $4.86 \pm 0.48 \mathrm{de}$ & $6.94 \pm 0.75 \mathrm{a}$ & $2.85 \pm 0.53 \mathrm{e}$ \\
MPE-W3 & $11.91 \pm 0.74 \mathrm{bcd}$ & $12.19 \pm 0.92 \mathrm{ab}$ & $11.52 \pm 1.66 \mathrm{a}$ & $5.29 \pm 0.79 \mathrm{cde}$ & $2.24 \pm 0.51 \mathrm{~d}$ & $7.47 \pm 0.92 \mathrm{ab}$ \\
H-S10 & $10.88 \pm 0.47 \mathrm{bcd}$ & $7.69 \pm 0.52 \mathrm{cdef}$ & $10.69 \pm 0.64 \mathrm{ab}$ & $4.28 \pm 0.47 \mathrm{de}$ & $7.19 \pm 0.65 \mathrm{a}$ & $3.91 \pm 0.47 \mathrm{cde}$ \\
MOH-S10 & $11.37 \pm 0.49 \mathrm{bcd}$ & $8.52 \pm 0.52 \mathrm{bcde}$ & $7.87 \pm 0.53 \mathrm{bc}$ & $7.79 \pm 0.56 \mathrm{ab}$ & $6.96 \pm 0.67 \mathrm{a}$ & $3.37 \pm 0.47 \mathrm{de}$ \\
Neem oil & $13.09 \pm 0.92 \mathrm{bcd}$ & $13.53 \pm 0.77 \mathrm{a}$ & $7.19 \pm 0.73 \mathrm{~cd}$ & $7.31 \pm 0.76 \mathrm{abc}$ & $3.94 \pm 0.81 \mathrm{bcd}$ & $5.20 \pm 0.85 \mathrm{~cd}$ \\
C-S10 & $12.44 \pm 0.62 \mathrm{bcd}$ & $7.26 \pm 0.46 \mathrm{cdef}$ & $9.79 \pm 0.61 \mathrm{abc}$ & $3.19 \pm 0.42 \mathrm{e}$ & $6.63 \pm 0.68 \mathrm{a}$ & $4.36 \pm 0.57 \mathrm{cde}$ \\
EOH-S10 & $12.71 \pm 0.64 \mathrm{bcd}$ & $5.88 \pm 0.47 \mathrm{efg}$ & $9.35 \pm 0.54 \mathrm{abc}$ & $3.62 \pm 0.47 \mathrm{e}$ & $7.85 \pm 0.61 \mathrm{a}$ & $4.17 \pm 0.54 \mathrm{cde}$ \\
MPE-MOH3 & $14.24 \pm 0.94 \mathrm{bcd}$ & $7.55 \pm 0.66 \mathrm{cdef}$ & $8.98 \pm 0.90 \mathrm{abc}$ & $9.00 \pm 0.62 \mathrm{ab}$ & $7.23 \pm 0.82 \mathrm{a}$ & $8.38 \pm 1.11 \mathrm{ab}$ \\
MPE-H3 & $14.64 \pm 1.03 \mathrm{bcd}$ & $9.54 \pm 0.95 \mathrm{cde}$ & $7.25 \pm 0.90 \mathrm{~cd}$ & $9.22 \pm 0.91 \mathrm{ab}$ & $4.78 \pm 0.89 \mathrm{bc}$ & $5.97 \pm 0.84 \mathrm{abcd}$ \\
MPE-W1 & $14.20 \pm 0.75 \mathrm{abc}$ & $9.67 \pm 1.18 \mathrm{bcde}$ & $8.82 \pm 0.88 \mathrm{abc}$ & $8.15 \pm 0.79 \mathrm{ab}$ & $4.57 \pm 0.82 \mathrm{~b}$ & $6.45 \pm 0.87 \mathrm{abc}$ \\
MPE-EOH3 & $13.96 \pm 0.69 \mathrm{ab}$ & $10.63 \pm 1.03 \mathrm{bcd}$ & $7.50 \pm 0.86 \mathrm{bcd}$ & $9.53 \pm 1.07 \mathrm{a}$ & $4.29 \pm 0.68 \mathrm{~b}$ & $8.04 \pm 0.93 \mathrm{ab}$ \\
MPE-W2 & $16.47 \pm 1.18 \mathrm{ab}$ & $10.77 \pm 0.73 \mathrm{bc}$ & $2.68 \pm 0.57 \mathrm{e}$ & $5.45 \pm 0.72 \mathrm{cde}$ & $5.15 \pm 0.85 \mathrm{~b}$ & $8.67 \pm 1.29 \mathrm{ab}$ \\
MPE-EA3 & $18.89 \pm 1.47 \mathrm{a}$ & $7.00 \pm 0.63 \mathrm{defg}$ & $8.76 \pm 1.08 \mathrm{abc}$ & $7.36 \pm 0.88 \mathrm{abc}$ & $3.44 \pm 0.61 \mathrm{bcd}$ & $5.46 \pm 0.70 \mathrm{bcd}$ \\
\hline
\end{tabular}

Values represent mean $\pm \mathrm{SE}$.

$* \mathrm{MFE}=$ M. azedarach fruit extract; MPE $=$ M. azedarach powder extract; $\mathrm{S} 10=$ solvent $(10 \%), \mathrm{C}=$ chloroform, $\mathrm{EOH}=\mathrm{ethanol}$, $\mathrm{EA}=$ ethyl acetate, $\mathrm{MOH}=$ methanol, $\mathrm{W}=$ water; concentrations: $1=500,000$ ppm, i.e., $1: 2(\mathrm{w}: \mathrm{v}), 2=200,000$ ppm, i.e., $1: 5(\mathrm{w}: \mathrm{v})$, $3=2,000$ ppm, i.e., 1:500 (w:v); UControl = untreated control; WControl = water control.

** Means within a column followed by the same letter are not significantly different.

in the range of $0.31 \%-1.92 \%$ and $0.07 \%-1.36 \%$, respectively.

There was also significant difference in \% L2 mortality $(F=9.509 ; \mathrm{df}=17(1,943) ; p<0.05)$ among $M$. azedarach extracts and the controls: water and untreated, except for MPE-W2 (Table 5). The highest L2 mortality was caused by MFE-W2 and MPE-MOH3 of $18.3 \%$ followed by MPE-C3, MPE-EOH3, MPE-W3, MPE-W1, MPE-H3, MPE-EA3 and MFE-W1 in the range of $13.44 \%-18.34 \%$. These treatments were comparable in their effect to neem oil of $14.5 \%$ and to their corresponding organic solvents. Specifically, there was significant difference in \% L2 dry $(F=15.805$; df $=17(1,943) ; p<0.05)$, brown $(F=10.963 ; \mathrm{df}=17$ $(1,943) ; p<0.05)$ and deformed $(F=10.040 ; \mathrm{df}=17$ $(1,943) ; p<0.05)$, among treatments. The highest $\%$ dry L2 was caused by MPE-W3 of $11.52 \%$ followed by other $M$. azedarach extracts and neem oil; all treatments were comparable in their effect to their corresponding solvents, except for the aqueous extracts MFE-W2, MPE-W3 and MPE-W1. Similarly, the highest \% brown dead L2 was caused by MFE-W2 of $9.54 \%$ followed by MPE-EOH3, MPE-H3, MFE-W1, MPE-W1, MPE-EA3 and MPE-C3 of $5.29 \%-9.53 \%$. All M. azedarach extracts were comparable to neem oil that caused $7.31 \%$ mortality, but only the latter extracts were not comparable in their effect to that of their corresponding organic solvents (Table 6). However, the deformed symptom on L2 was very low in the range of $0.32 \%-2.23 \%$.

\subsubsection{Indirect Effects on Larvae (L3)}

Results of this experiment indicated that there was high indirect effect on larval instar L3, developing from treated L1 and L2 larval instars. There was significant difference in \% dead L3 ( $F=4.900$; df $=$ $17(1,943) ; p<0.05)$ among treatments (Table 5). The highest L3 mortality was caused by MPE-MOH3 and MFE-W1 of $15.61 \%$ and $15.33 \%$, respectively, followed by MPE-W2; these extracts were 
significantly higher in their effect from that of neem oil that caused only $9.14 \%$ mortality and from that of their corresponding solvent control (Table 5). Specifically, there was significant difference in \% L3 dry $(F=18.625 ; \mathrm{df}=17(1,943) ; p<0.05)$, brown $(F$ $=13.618 ; \mathrm{df}=17(1,943) ; p<0.05)$, deformed $(F=$ 4.168; $\mathrm{df}=17(1,943) ; p<0.05)$ and shrunk $(F=$ 3.998; $\mathrm{df}=17(1,943) ; p<0.05)$ among treatments. The dry L3 symptom caused by the plant extracts and neem oil was comparable and sometimes lower than that of the corresponding control (Table 6). However, the highest brown symptom on L3 was caused by MPE-W2 and MFE-W1 of $8.67 \%$ followed by MPE-MOH3, MPE-EOH3, MFE-W2, MPE-W3, MPE-C3 and MPE-EA3 of 5.46\%-8.38\% mortality. All these extracts were comparable in their effect to neem oil, except MPE-W1, but were significantly different in their effect from their corresponding solvent control. On the other hand, deformed and shrunk symptoms on L3 were very low less than $0.49 \%$ and $0.29 \%$, respectively.

Thus, there was high direct mortality effect on L1 larval instar by seven bioactive $M$. azedarach extracts: MPE-W2, MPE-EA3, MPE-EOH3, MPE-W1, MPE-W3, MFE-W2 and MFE-W1, but only the latter three aqueous extracts were bioactive against L2 instar. On the other hand, MPE-MOH3, MPE-W2 and MFE-W1 caused the highest indirect effect on L3 larvae. Thus, the latter extract MFE-W1 was effective against L1, L2 and L3, but neem oil was effective against L1 and L2 larvae only. Specifically, these extracts MPE-W3, MPE-W1, MFE-W2 caused high dry symptom against L1 and L2, but there was no dry symptom detected on L3 by these extracts. Furthermore, the high brown symptom against all larval instars was caused by MPE-EOH3, MPE-W1, MFE-W2 and MFE-W1. Kona et al. [26] studied also the effect of botanical extracts of neem and Jatropha (J. curcus L.) on larvae of T. absoluta in the laboratory. Groups of 15-20 recently hatched larvae (L1) of T. absoluta were placed in Petri dishes; each Petri dish contained a piece of fresh tomato leaf, previously immersed for $5 \mathrm{~s}$ in each of the different concentrations of the extracts. After $24 \mathrm{~h}$, larval mortality ranged from 33\%-46.6\% with the four concentrations of the neem seed extract, and by the 4th day, higher larval mortality up to $100 \%$ was obtained. Similarly, Jatropha seed extract induced larval mortality of $23 \%-48.5 \%$ for all concentrations after $24 \mathrm{~h}$, reaching high larval mortality of $85 \%-100 \%$ by the 4 th day. However, in the current study, L1 mortality due to $M$. azedarach extracts was in the range of $24.11 \%-27.54 \%$, whereas L2 and L3 mortality was in the range of $13.44 \%-18.43 \%$ and $9.14 \%-15.61 \%$, respectively. Thus, total larval mortality at end of this experiment was $61.58 \%$ maximum due to extracts and was $52.25 \%$ due to neem oil, but larval mortality did not reach $100 \%$ mortality as early larval instars were inside their mines on leaves of tomato plants in this experiment, simulating field application of pesticides against the leafminer larvae.

\subsubsection{Pupa Instar}

There was a limited direct effect on pupae of the tomato leafminer by $M$. azedarach extracts. Data analysis indicated that there was significant difference in $\%$ dead pupae $(F=3.142 ; \mathrm{df}=17(809) ; p<0.05)$ and \% emerging moths $(F=5.114 ; \mathrm{df}=17$ (809); $p<$ 0.05) among treatments (Table 7). M. azedarach extract (MFE-W1) caused the highest numerical \% of dead pupae of $14.07 \%$ compared to other treatments and was significantly different in its effect from the controls, untreated and water. This high effect on pupae caused by MFE-W1 could be attributed to its high concentration of 500,000 ppm compared to other extracts of lower concentrations. On the other hand, the lowest \% of emerging moths of $12.59 \%$ was caused by MFE-W1 which was significantly different in its effect from all other treatments including the controls; this indicates that the latter M. azedarach extract might have systemic physiological effect on developing moths inside treated pupae. Specifically, there was significant difference in \% pupae having part of emerging adults inside pupa $(F=2.353 ; \mathrm{df}=17$ 
Table 7 Direct effects of M. azedarach extracts and neem oil on T. absoluta pupae under laboratory conditions.

\begin{tabular}{lllll}
\hline Treatment* & \% Dead pupae & \% Emerging moths & $\begin{array}{l}\text { \% Pupae with part of } \\
\text { emerging moth inside }\end{array}$ & \% Dry brown pupae \\
\hline MPE-W3 & $8.89 \pm 3.41 \mathrm{ab}$ & $48.15 \pm 4.68 \mathrm{a}$ & $3.70 \pm 1.57 \mathrm{ab}$ & $0.00 \pm 0.00 \mathrm{~b}$ \\
UControl & $0.74 \pm 0.74 \mathrm{c}$ & $46.67 \pm 5.74 \mathrm{ab}$ & $0.00 \pm 0.00 \mathrm{~b}$ & $0.00 \pm 0.00 \mathrm{~b}$ \\
C-S10 & $6.66 \pm 2.50 \mathrm{ab}$ & $42.22 \pm 5.54 \mathrm{abc}$ & $0.00 \pm 0.00 \mathrm{~b}$ & $1.48 \pm 1.03 \mathrm{ab}$ \\
MPE-W1 & $3.70 \pm 1.90 \mathrm{abc}$ & $39.26 \pm 5.92 \mathrm{abc}$ & $0.00 \pm 0.00 \mathrm{~b}$ & $0.00 \pm 0.00 \mathrm{~b}$ \\
H-S10 & $2.96 \pm 1.42 \mathrm{bc}$ & $38.52 \pm 5.79 \mathrm{abc}$ & $0.00 \pm 0.00 \mathrm{~b}$ & $0.74 \pm 0.74 \mathrm{ab}$ \\
WControl & $2.96 \pm 1.42 \mathrm{bc}$ & $37.78 \pm 5.14 \mathrm{abc}$ & $0.00 \pm 0.00 \mathrm{~b}$ & $0.00 \pm 0.00 \mathrm{~b}$ \\
MFE-W2 & $7.41 \pm 2.97 \mathrm{ab}$ & $37.04 \pm 4.76 \mathrm{abc}$ & $0.00 \pm 0.00 \mathrm{~b}$ & $0.00 \pm 0.00 \mathrm{~b}$ \\
MOH-S10 & $7.41 \pm 2.78 \mathrm{ab}$ & $36.29 \pm 4.83 \mathrm{abc}$ & $0.00 \pm 0.00 \mathrm{ab}$ & $0.00 \pm 0.00 \mathrm{~b}$ \\
EA-S10 & $5.19 \pm 1.82 \mathrm{abc}$ & $36.29 \pm 5.27 \mathrm{abc}$ & $1.48 \pm 1.03 \mathrm{ab}$ & $0.00 \pm 0.00 \mathrm{~b}$ \\
MPE-C3 & $8.89 \pm 3.24 \mathrm{ab}$ & $35.55 \pm 4.66 \mathrm{abc}$ & $0.74 \pm 0.74 \mathrm{ab}$ & $0.00 \pm 0.00 \mathrm{~b}$ \\
MPE-MOH3 & $8.15 \pm 3.20 \mathrm{ab}$ & $35.55 \pm 4.66 \mathrm{abc}$ & $2.96 \pm 1.42 \mathrm{a}$ & $0.00 \pm 0.00 \mathrm{~b}$ \\
Neem oil & $8.89 \pm 3.41 \mathrm{ab}$ & $33.33 \pm 5.19 \mathrm{abc}$ & $0.74 \pm 0.74 \mathrm{ab}$ & $0.00 \pm 0.00 \mathrm{~b}$ \\
MPE-W2 & $11.11 \pm 3.51 \mathrm{ab}$ & $32.59 \pm 4.03 \mathrm{abc}$ & $0.74 \pm 0.74 \mathrm{ab}$ & $0.00 \pm 0.00 \mathrm{~b}$ \\
MPE-EA3 & $11.11 \pm 3.96 \mathrm{ab}$ & $30.37 \pm 4.47 \mathrm{bc}$ & $2.96 \pm 1.42 \mathrm{ab}$ & $2.22 \pm 1.25 \mathrm{ab}$ \\
EOH-S10 & $6.67 \pm 2.00 \mathrm{ab}$ & $29.63 \pm 4.64 \mathrm{bc}$ & $0.00 \pm 0.00 \mathrm{~b}$ & $2.96 \pm 1.42 \mathrm{a}$ \\
MPE-EOH3 & $6.67 \pm 2.92 \mathrm{ab}$ & $28.89 \pm 5.25 \mathrm{c}$ & $1.48 \pm 1.03 \mathrm{ab}$ & $0.74 \pm 0.74 \mathrm{ab}$ \\
MPE-H3 & $9.63 \pm 3.28 \mathrm{ab}$ & $25.93 \pm 4.48 \mathrm{c}$ & $0.00 \pm 0.00 \mathrm{~b}$ & $0.74 \pm 0.74 \mathrm{ab}$ \\
MFE-W1 & $14.07 \pm 4.55 \mathrm{a}$ & $12.59 \pm 3.05 \mathrm{~d}$ & $1.48 \pm 1.03 \mathrm{~b}$ & $2.96 \pm 1.42 \mathrm{ab}$ \\
\hline Valus repres & & &
\end{tabular}

Values represent mean $\pm \mathrm{SE}$.

$* \mathrm{MFE}=$ M. azedarach fruit extract; MPE = M. azedarach powder extract; S10 = solvent $(10 \%) ; \mathrm{C}=$ chloroform; $\mathrm{EOH}=\mathrm{ethanol}$; $\mathrm{EA}=$ ethyl acetate; $\mathrm{MOH}=$ methanol; $\mathrm{W}=$ water; concentrations: $1=500,000$ ppm, i.e., $1: 2(\mathrm{w}: \mathrm{v}), 2=200,000$ ppm, i.e., $1: 5(\mathrm{w}: \mathrm{v})$, $3=2,000$ ppm, i.e., 1:500 (w:v); UControl = untreated control; WControl = water control.

** Means within a column followed by the same letter are not significantly different.

(809); $p=0.002)$, dry $(F=2.381 ; \mathrm{df}=17$ (809); $p=$ $0.001)$, deformed $(F=2.118 ; \mathrm{df}=17$ (809); $p=0.005)$ and diseased $(F=2.178 ; \mathrm{df}=17(809) ; p=0.004)$ among treatments. The highest \% pupae having part of emerging adult inside pupa is caused by MPE-W3 and MPE-EA3 of $3.70 \%$ and $2.96 \%$, respectively; the latter extract also caused highest $\%$ of dry brown pupae of $2.22 \%$ (Table 7 ). However, highest $\%$ of deformed and diseased pupae of $1.48 \%$ and $2.22 \%$, respectively, was detected in MPE-W2 treatment. Furthermore, there was no significant difference in $\%$ dead pupae and \% emerging moths between each $M$. azedarach extract and its corresponding organic solvent $(10 \%)$ as control, but all organic solvents were comparable in their effect on pupae to that of the water control. This indicates that the pupa cuticle is well protected and it seems that higher concentrations of $M$. azedarach extracts in organic solvents are needed to extract bioactive materials that can penetrate pupa cuticle; especially that symptoms of non-healthy pupae were detected at low concentration of 2,000 ppm.

\subsubsection{Consecutive Treatments}

There was significant difference in \% dead eggs $(F$ $=232.705 ; \mathrm{df}=17$ (3,077); $p<0.05)$, after the 1st application of treatments on leafminer eggs, among $M$. azedarach extracts $(2,000 \mathrm{ppm})$ and all controls, solvents and untreated control. The highest mortality effect on Tuta eggs was caused by MPE-W1 and MFE-W1, both of $500,000 \mathrm{ppm}$ of $19.99 \%$ and $17.01 \%$, respectively, followed by neem oil causing mortality of $14.42 \%$. All M. azedarach extracts were significantly different in \% dead eggs compared to their corresponding controls (Table 8). However, the results in the above experiment against Tuta eggs indicated that MFE-W2 (200,000 ppm) caused significant high mortality of $31.91 \%$ followed by MFE-MOH2, neem oil and MFE-EA2 causing \% egg mortality of $29.11 \%, \quad 32.59 \%$ and $41.77 \%$, 
respectively (Table 3); this could be attributed to higher concentration of these $M$. azedarach extracts compared to those used in the consecutive treatment experiment. Furthermore, the difference in neem oil effect could be related to higher number of observations for dead eggs in the previous experiment than the current one of 13 and seven observations, respectively.

Furthermore, there was significant difference in \% dead larvae $(F=109.731 ; \mathrm{df}=17(3,077) ; p<0.05)$, after the 2nd application of treatments on leafminer larvae (L1-L2) among M. azedarach extracts and all controls, solvents and untreated control. The highest mortality effect on Tuta larvae was caused by MPE-W3 of 40.15\%, followed by MPE-W2, MPE-H3, MPE-EA3, MFE-W2, MPE-C3, MPE-MOH3, MPE-EOH3, MFE-W1 and MPE-W1 in the range of $33.29 \%-39.58 \%$. All M. azedarach extracts were comparable in their effect to that of neem oil causing mortality of $36.61 \%$ (Table 8 ). However, the results in the above experiment against larvae (L1-L2) indicated that the highest L1 mortality was caused by neem oil of $28.61 \%$ followed by MPE-W2, MPE-EA3, MPE-EOH3, MPE-W1, MPE-H3, MPE-C3 and MPE-W3 in the range of $24.11 \%-27.54 \%$ (Table 5); cumulative $\%$ dead L1 and L2 caused by MPE-W1, MPE-W3 and MFE-W1 would be 42.21\%, 41.33\% and $32.18 \%$, respectively (deduced from Table 5). These are comparable to results of consecutive treatments, after the 2nd treatment on L1-L2, caused by the latter extracts of $33.29 \%, 40.15 \%$ and $34.52 \%$, respectively (Table 8).

Consequently, there was significant difference in \% dead pupae $(F=9.763 ; \mathrm{df}=17(3,077) ; p<0.05)$ and $\%$ live moths emerging from treated pupae $(F=142.150$; $\mathrm{df}=17(3,077) ; p<0.05)$, after the 3rd application of treatments on leafminer pupae, among $M$. azedarach extracts and all controls, solvents and untreated control (Table 8). However, all M. azedarach extracts and neem oil caused less or comparable effect on pupae

Table 8 Effect of three consecutive sprays of $M$. azedarach extracts and neem oil on $T$. absoluta immature instars under laboratory conditions.

\begin{tabular}{lllll}
\hline Treatment* & \% Dead eggs & \% Dead larvae & \% Dead pupae & \% Emerging moths \\
\hline UControl & $1.05 \pm 0.13 \mathrm{j}^{* *}$ & $6.86 \pm 1.06 \mathrm{c}$ & $1.14 \pm 0.23 \mathrm{a}$ & $4.63 \pm 0.95 \mathrm{a}$ \\
WControl & $1.19 \pm 0.15 \mathrm{j}$ & $8.17 \pm 1.18 \mathrm{c}$ & $0.71 \pm 0.14 \mathrm{~b}$ & $5.05 \pm 1.02 \mathrm{a}$ \\
C-S10 & $2.96 \pm 0.21 \mathrm{i}$ & $20.96 \pm 2.24 \mathrm{~b}$ & $0.42 \pm 0.08 \mathrm{de}$ & $2.08 \pm 0.44 \mathrm{~b}$ \\
EOH-S10 & $2.97 \pm 0.21 \mathrm{i}$ & $21.16 \pm 2.26 \mathrm{~b}$ & $0.13 \pm 0.05 \mathrm{e}$ & $1.99 \pm 0.43 \mathrm{~b}$ \\
H-S10 & $2.99 \pm 0.14 \mathrm{i}$ & $19.21 \pm 2.10 \mathrm{~b}$ & $0.32 \pm 0.07 \mathrm{de}$ & $2.21 \pm 0.47 \mathrm{~b}$ \\
MOH-S10 & $3.68 \pm 0.17 \mathrm{i}$ & $19.15 \pm 2.10 \mathrm{~b}$ & $0.30 \pm 0.08 \mathrm{de}$ & $2.07 \pm 0.46 \mathrm{~b}$ \\
EA-S10 & $4.98 \pm 0.15 \mathrm{~h}$ & $19.89 \pm 2.14 \mathrm{~b}$ & $0.23 \pm 0.07 \mathrm{de}$ & $2.43 \pm 0.48 \mathrm{~b}$ \\
MPE-W2 & $6.49 \pm 0.30 \mathrm{~g}$ & $39.58 \pm 2.92 \mathrm{a}$ & $0.46 \pm 0.08 \mathrm{bcd}$ & $0.58 \pm 0.13 \mathrm{c}$ \\
MPE-W3 & $7.28 \pm 0.34 \mathrm{fg}$ & $40.15 \pm 2.93 \mathrm{a}$ & $0.39 \pm 0.07 \mathrm{bcd}$ & $0.48 \pm 0.11 \mathrm{~cd}$ \\
MPE-MOH3 & $8.30 \pm 0.52 \mathrm{f}$ & $38.29 \pm 2.83 \mathrm{a}$ & $0.58 \pm 0.09 \mathrm{bc}$ & $0.32 \pm 0.08 \mathrm{~cd}$ \\
MPE-H3 & $7.80 \pm 0.22 \mathrm{f}$ & $39.58 \pm 2.89 \mathrm{a}$ & $0.33 \pm 0.07 \mathrm{cde}$ & $0.44 \pm 0.10 \mathrm{~cd}$ \\
MPE-C3 & $9.84 \pm 0.48 \mathrm{e}$ & $38.30 \pm 2.84 \mathrm{a}$ & $0.18 \pm 0.05 \mathrm{de}$ & $0.47 \pm 0.10 \mathrm{~cd}$ \\
MPE-EA3 & $9.82 \pm 0.39 \mathrm{e}$ & $39.22 \pm 2.87 \mathrm{a}$ & $0.47 \pm 0.09 \mathrm{bcd}$ & $0.38 \pm 0.09 \mathrm{~cd}$ \\
MFE-W2 & $12.10 \pm 0.51 \mathrm{~d}$ & $38.86 \pm 2.81 \mathrm{a}$ & $0.19 \pm 0.04 \mathrm{de}$ & $0.36 \pm 0.08 \mathrm{~cd}$ \\
MPE-EOH3 & $11.99 \pm 0.38 \mathrm{~d}$ & $37.97 \pm 2.74 \mathrm{a}$ & $0.32 \pm 0.07 \mathrm{de}$ & $0.40 \pm 0.11 \mathrm{~cd}$ \\
Neem oil & $14.42 \pm 0.48 \mathrm{c}$ & $36.61 \pm 2.68 \mathrm{a}$ & $0.21 \pm 0.05 \mathrm{de}$ & $0.40 \pm 0.08 \mathrm{~cd}$ \\
MFE-W1 & $17.01 \pm 0.63 \mathrm{~b}$ & $34.52 \pm 2.54 \mathrm{a}$ & $0.24 \pm 0.06 \mathrm{de}$ & $0.28 \pm 0.07 \mathrm{~d}$ \\
MPE-W1 & $19.99 \pm 0.83 \mathrm{a}$ & $33.29 \pm 2.43 \mathrm{a}$ & $0.26 \pm 0.61 \mathrm{de}$ & $0.39 \pm 0.09 \mathrm{~cd}$ \\
\hline
\end{tabular}

Values represent mean \pm SE.

$* \mathrm{MFE}=$ M. azedarach fruit extract; $\mathrm{MPE}=$ M. azedarach powder extract; $\mathrm{S} 10=$ solvent $(10 \%) ; \mathrm{C}=$ chloroform; $\mathrm{EOH}=\mathrm{ethanol}$; $\mathrm{EA}=$ ethyl acetate; $\mathrm{MOH}=$ methanol; $\mathrm{W}=$ water; concentrations: $1=500,000$ ppm, i.e., $1: 2(\mathrm{w}: \mathrm{v}), 2=200,000$ ppm, i.e., $1: 5(\mathrm{w}: \mathrm{v})$, $3=2,000$ ppm, i.e., 1:500 (w:v); UControl $=$ untreated control; WControl $=$ water control.

** Means within a column followed by the same letter are not significantly different. 
to their corresponding control; the extracts causing dead pupae in the range of $0.74 \%-2.96 \%$, whereas in the above experiment related to direct effect of $M$. azedarach extracts on pupae; highest $\%$ dead pupae recorded due to MFE-W1 was $14.07 \%$ (Table 7). Similarly, \% emerging moths from treated pupae was significantly less in $M$. azedarach extracts than their corresponding controls, but was comparable to that of neem oil of $0.4 \%$; aqueous $M$. azedarach extracts causing low moth emergence of $0.28 \%-0.58 \%$ compared to the water and untreated control of $5.05 \%$ and $4.63 \%$, respectively. Other M. azedarach extracts caused low moth emergence of $0.32 \%-0.47 \%$ compared to their corresponding organic solvents of $1.99 \%-2.43 \%$ (Table 8). However, lowest \% emergence of moths from treated pupae in above experiment was $12.59 \%$ caused by MFE-W1 (Table 7).

On the other hand, the indirect effect of $M$. azedarach extracts on pupae developing from treated eggs caused $0.14 \%-0.89 \%$ moth emergence versus $9.37 \%$ in the control. Thus, consecutive treatments of M. azedarach extracts and cumulative effect of their bioactive components lead to very low number of newly emerging moths which verifies the systemic effect of these extracts that affect early immature instars as eggs and larvae. Furthermore, the insect growth regulatory effect of these botanical products against $T$. absoluta is revealed further in their high effect on pupa development into newly emerging adult moths.

In this study, the bioactivity effect of the plant extracts against $T$. absoluta is related to several factors as the insect instar, plant materials formulation and concentrations of the plant extracts. Higher direct bioactivity against eggs and larvae than against pupae of the tomato leafminer was detected. Whereas, there were significant indirect affects in form of low number of larval instar L3 and newly emerging moths from pupae. The powder formulation of $M$. azedarach freeze dried fruits showed comparable direct effects to crushed $M$. azedarach fruits against eggs, larvae and pupae of the leafminer. Furthermore, the different concentrations (500,000, 200,000 and 2,000 ppm) of the MP aqueous extracts were comparable in their effect against all instars of the leafminer.

Oils are known to act as surfactants, reduce surface tension and increase the penetration of certain biopesticides [27]; their toxicity is affected by different factors including insect cuticle properties, ambient temperature, and volume of oil molecules [28]. M. azedarach extracts in methanol (200,000 ppm) caused significant mortality of eggs and dry eggs of $29.11 \%$, but in presence of oil with this extract the mortality increased significantly to $37.69 \%$ and $37.56 \%$ in terms of dead and dry eggs, respectively (Table 3 ).

Similar to the current study, under no-choice conditions, higher concentrations of methanolic extracts of $M$. azedarach seed extracts caused proportionate reductions in the number of eggs laid of noctuid spotted bollworm Earias vittella $\mathrm{F}$. (Lepidoptera). Eggs laid on extract-treated oviposition substrate exhibited reduced hatching. The extracts also manifested repellent activity against adults by reducing the number of eggs laid even when the ovipositing females were not in direct contact with the extracts. Furthermore, adults fed on an extract-containing sucrose diet laid significantly fewer eggs with poor hatching, but there was no egg laying when the moths were fed on a sucrose diet containing $10 \% M$. azedarach extracts [29].

Other factors also contribute to the effect of active ingredients of plant extracts as seed drying, exposure to sunlight, storage and the method of extraction [30]. A search for suitable organic solvents to extract insecticidal secondary plant compounds from the plant is always needed. Plant extracts might also have low residual stability on plants especially that it is known that insecticides of biological or botanical origin are susceptible to ultra violet light degradation, resulting in reduced efficacy [31]. Thus, prolongation of the botanical insecticidal extract on foliage by adding oil 
might increase the pesticide effectiveness and enhance its biological activity [17].

Considering the high risks and hazards of broad spectrum synthetic insecticides, these natural plant extracts constitute a cheap, valuable, safe and environment friendly alternative compounds in insect pest management. Extracts of the seeds of $M$. azedarach tree are known to contain several limonoids and show excellent insecticidal activity [32-34]; $M$. azedarach stem bark contains the limonoid toosendanin which is the primary active ingredient of a botanical insecticide lately developed in China [35]. Furthermore, the concentration of MFE need to be studied to determine $\mathrm{LD}_{50}$ of these extracts against the tomato leafminer eggs and larval instars. More investigations with new plant materials in the future will constitute an asset in the field of botanical pesticides.

Thus, the micronized sulfur, often used as a fungicide in organic farming, and aqueous MFE have potential repellent activity against the adult leafminer instar of T. absoluta. M. azedarach extracts in ethyl acetate, water and methanol $(200,000 \mathrm{ppm})$ with and without oil were found to be effective against eggs of the leafminer. It is important to note further that larvae (L1) of T. absoluta were affected by MPE-W3 (2,000 ppm), similar to MPE-W2 and MPE-W1 (200,000 ppm and 500,000 ppm, respectively). Hence, M. azedarach in form of powder formulation can be applied as aqueous sprays at field rate of $2 / 3$ $\mathrm{kg}$ MP in $1,000 / 1,500 \mathrm{~L} / \mathrm{ha}$. As for $M$. azedarach extracts in different solvents, it is important to fractionate the most bioactive extracts that have shown significant difference in effect against the leafminer compared to their corresponding control. For example, MFE-EA2, MFE-W2 and MFE-MOH2 against egg instar; MPE2-W2, MPE-EA3, MPE-EOH3, MPE-W1, MPE-W3, MFE-W2 and MFE-W1 against larvae instars; MFE-W1 against Tuta pupae. Similarly, taking into consideration the consecutive treatments effect, analysis of the bioactive extracts that contributed to lowest newly emerging moths in the range of $0.28 \%-0.58 \%$ after three consecutive sprays would include MFE-W1, MPE-MOH3, MFE-W2, MPE-EA3, MPE-W1, MPE-EOH, MPE-H3, MPE-C3, MPE-W3 and MPE-W2. Thus, the potential extracts of $M$. azedarach might contribute to lower leafminer populations in a comprehensive pest management program in local communities, pending cultivation of this indigenous plant species.

\section{Conclusions}

Some studies have dealt with the potential effect of M. azedarach and other Meliaceae species against $T$. absoluta in form of adult repellency, abnormal larval behavior and insecticidal toxicity to the pest. Although, the importance and application of botanical products, mainly of the neem tree A. indica, in organic farming systems are recognized, there are a few studies related to the indigenous M. azedarach species against the tomato leafminer which is considered a major pest in production of seasonal cops as vegetables. In the present work, $M$. azedarach aqueous extracts open the chance for local use of this plant resource in a powder formulation at low concentration of 2,000 ppm instead of crushing many fruits that might exploit the resource. Extracts of MP proved to be efficient in controlling different instars of the pest during its life cycle, especially if used in consecutive applications on infested plants. This result indicates that the latter extracts can be used in alternation with other biorational products as neem oil (knowing that Melia species have no azadirachtin and have other terpenoids as Meliatoxins), sulfur, mineral oil and thyme oil, to delay pest resistance to different biorational products. Furthermore, the aqueous extracts were as efficient as other $M$. azedarach extracts in organic solvents; this result open the scope for future biochemical analysis of all bioactive extracts of local indigenous $M$. azedarach. 


\section{Acknowledgments}

The authors would like to thank the National Center for Scientific Research (NCSR), Beirut, Lebanon for funding this research study that helped a few graduate students to accomplish their research studies at the Faculty of Agriculture and Veterinary Sciences, Lebanese University.

\section{References}

[1] European Plant Protection Organization (EPPO). 2005. "EPPO Datasheets on Quarantine Pests: Tuta absoluta." EPPO Bulletin 35: 434-5. http://www.eppo.org/QUARANTINE/insects/Tuta_absol uta/DS_Tuta_absoluta.pdf.

[2] Insecticide Resistance Action Committee (IRAC). 2010. "The Tomato Leafminer, Tuta absoluta, Recommendations for Sustainable and Effective Resistance Management." http://www.irac_online.org.

[3] Bloem, S., and Spaltenstein, E. 2011. "New Pest Response Guidelines: Tomato Leafminer (Tuta absoluta)." USDA, Emergency and Domestic Programs 5/2011-01.

[4] Desneux, N., Wajnberg, E., Wyckhuys, K. A. G., Burgio, G., Arpaia, S., Narvaez-Vasquez, C. A., Gonzalez-Cabrera, J., Ruescas, D. C., Tabone, E., Frandom, J., Pizzol, J., Poncet, C., Cabello, T., and Urbaneja, A. 2010. "Biological Invasion of European Tomato Crops by Tuta absoluta: Ecology, Geographic Expansion and Prospects for Biological Control." J. Pest Sci. 83 (3): 197-215.

[5] Moreno, S. C., Carvalho, G. A., Picanc, M. C., Morais, E. G. F., and Pereira, R. M. 2011. "Bioactivity of Compounds from Acmella oleracea against Tuta absoluta (Meyrick) (Lepidoptera: Gelechiidae) and Selectivity to Two Non-target Species." Pest Management Sci. 8: 23-32.

[6] Campbell, C. D., Walgenbach, J. F., and Kennedy, G. C. 1991. "Effect of Parasitoids on Lepidopterous Pests in Insecticide-Treated and Untreated Tomatoes in Western North Carolina." J. Econ. Entomol. 84: 1662-7.

[7] Walgenbach, J. F., Leidy, R. B., and Sheets, T. J. 1991. "Persistence of Insecticides on Tomato Foliage and Implications for Control of Tomato Fruit Worm (Lepidoptera: Noctuidae).” J. Econ. Entomol. 84: 978-86.

[8] Lietti, M. M. M., Botto, E., and Alzogaray, R. A. 2005. "Insecticide Resistance in Argentine Populations of Tuta absoluta (Meyrick) (Lepidoptera: Gelechiidae)." Neotropical Entomol. 34 (1): 113-9.

[9] Roditakis, E., Vasakis, E., García-Vidal, L. M., del Rosario Martínez-Aguirre, J. L., Rison, M. O.,
Haxaire-Lutun, R., Nauen, Tsagkarakou, A., and Bielza, P. 2018. "A Four-Year Survey on Insecticide Resistance and Likelihood of Chemical Control Failure for Tomato Leafminer Tuta absoluta in the European/Asian Region.” J. Pest Sci. 91 (1): 421-35.

[10] Farombi, E. O. 2003. "African Indigenous Plants with Chemotherapeutic Potentials and Biotechnological Approach to the Production of Bioactive Prophylactic Agents." African J. Biotech. 2 (12): 662-71.

[11] Ascher, K. R. S. 1993. "Nonconventional Insecticidal Effects of Pesticides Available from the Neem Tree, Azadirachta indica." Arch. Insect Biochem. Physiol. 22: 433-49.

[12] Tomé, H. V. V., Martins, J. C., Corrêa, A. S., Galdino, T. V. S., Picanço, M. C., and Guedes, R. N. C. 2013. "Azadirachtin Avoidance by Larvae and Adult Females of the Tomato Leafminer Tuta absoluta." Crop Protection 46: 63-9.

[13] Da Cuncha, U. S., Vendramim, J. D., Rocha, W., and Vieira, P. C. 2006. "Fractions of Trichilia pallens with Insecticidal Activity against Tuta absoluta." Pesquisa Agropecuária Brasileira 41 (11): 1579-85.

[14] Terzidis, A. N., Wilcockson, S., and Leifert, C. 2014. "The Tomato Leafminer (Tuta absoluta): Conventional Pest Problem, Organic Management Solutions." Org. Agr. 4: 43-61.

[15] Anonymous. 2010. IBM SPSS. Verisign Class 3 Code Signing 2010 CA. International Business Machines Corporation, Illinois, Chicago, USA.

[16] Zappala, L., Siscaro, G., Biondi, A., Molla, O., Gonzalez-Cabrera, J., and Urbaneja, A. 2011. "Efficacy of Sulphur on Tuta absoluta and Its Side Effects on the Predator Nesidiocoris tenuis." J. Appl. Entomol. 136: 401-9.

[17] Sundaram, K. M. S. 1996. "Azadirachtin Biopesticide: A Review of Studies Conducted on Its Analytical Chemistry, Environmental Behavior and Biological Effects." $J$. Environ. Sci. and Health B 31: 913-48.

[18] Estay, P. 2009. "Polilla del Tomate Tuta absoluta (Meyrick)." http://alerce.inia.cl docs/Informativos/Informativo09.pdf. (English abstract)

[19] Seljasen, R., and Meadow, R. 2006. "Effects of Neem on Oviposition and Egg and Larval Development of Mamestra brassicae L.: Dose Response, Residual Activity, Repellent Effect and Systemic Activity in Cabbage Plants." Crop Prot. 25: 338-45.

[20] Tavares, W. S., Cruz, I., Fonseca, F. G., Gouveia, N. L., Serrão, J. E., and Zanuncio, J. C. 2010. "Deleterious Activity of Natural Products on Postures of Spodoptera frugiperda (Lepidoptera: Noctuidae) and Diatraea saccharalis (Lepidoptera: Pyralidae)." Z Naturfosch C. 65 (5-6): 412-8. 
[21] Kordan, B., Kosewska, A., Szumny, A., Wawrzeńczyk, C., and Gabryś, B. 2013. "Effects of Aromatic Plant Extracts and Major Terpenoid Constituents on Feeding Activity of the Horse-Chestnut Leafminer Cameraria ohridella Deschka \& Dimic." Polish J. Natural Sci. 28 (1): 53-62.

[22] Trindade, R. C. P., Marques, I. M. R., Xavier, H. S., and De Oliveira, J. V. 2000. "Neem Seed Kernel Extract and the Tomato Leafminer Egg and Larvae Mortality." Scientia Agricola 57: 407-13.

[23] Braham, M., and Hajji, L. 2012. "Management of Tuta absoluta (Lepidoptera, Gelechiidae) with Insecticides on Tomatoes.” In: Insecticides - Pest Engineering, edited by Perveen, F. InTech, 333-54. http://www.intechopen.com/.

[24] Nilahyane, A., Bouharroud, R., Hormatallah, A., and Taadaouit, N. A. 2012. "Larvicidal Effect of Plant Extracts on Tuta absoluta (Lepidoptera: Gelechiidae)." IOBC/WRPS Bulletin 80: 305-10.

[25] Ghanim, N. M., and Abdel Ghani, S. B. 2014. "Controlling Tuta absoluta (Lepidoptera: Gelechiida) and Aphis gossypii (Hemiptera: Aphididae) by Aqueous Plant Extracts." Life Sci. J. 11 (3): 299-307.

[26] Kona, M. E. N., Taha, K. A., and Mahmoud, E. E. M. 2014. "Effects of Botanical Extracts of Neem (Azadirachta indica) and Jatropha (Jatropha curcus) on Eggs and Larvae of Tomato Leafminer, Tuta absoluta (Meyrick) (Lepidoptera: Gelechiidae).” Persian Gulf Crop Protection 3 (3): 41-6.

[27] Dias, C., Carsia, P., Simoes, N., and Oliveira, L. 2005. "Efficacy of Bacillus thuringiensis against Phyllocnistis citrella (Lepidoptera: Phyllocnitidae).” J. Econ. Entomol. 98: 1880-3.

[28] Amiri-Besheli, B. 2008. "Efficacy of Bacillus thuringiensis, Mineral Oil, Insecticidal Emulsion and Insecticidal Gel against Phyllocnistis citrella Stainton
(Lepidoptera: Gracillariidae).” Plant Protect. Sci. 44 (2): 68-73.

[29] Gajmer, T., Singh, R., Sainsi, R. K., and Kalidhar, S. B. 2002. "Effect of Methanolic Extracts of Neem (Azadirachta indica A. Juss) and Bakain (Melia azedarach L.) Seeds on Oviposition and Egg Hatching of Earias vitella (Fab.) (Lep. Noctuidae).” J. App. Entom. 126 (5): 238-43.

[30] Ermel, K., Pahlich, E., and Schmutterer, H. 1984. "Comparison of the Azadirachtin Content of Neem Seeds from Ecotypes of Asian and African Origin.” In Natural Pesticides from the Neem Tree (Azadirachta indica A. Juss) and Other Tropical Plants, edited by Schmutterer, H., Ascher, K. R. S. Eschborn, Germany, GTZ, 91-4.

[31] Sundaram, K. M. S., Campbell, R., Sloane, L., and Studens, J. 1995. "Uptake, Translocation, Persistence and Fate of Azadirachtin in Aspen Plants (Populus tremuloides Michx.) and Its Effect on Pestiferous Two-Spotted Spider Mite (Tetranychus urticae Koch).” Crop Protection 14: 415-21.

[32] Srivastava, S. D. 1986. "Limonoids from the Seeds of Melia azedarach.” J. Nat. Prod. 49: 56-61.

[33] Lee, S. M., Klocke, J. A., Barnby, M. A., Yamasaki, R. B., and Balandrin, M. F. 1991. "Insecticidal Constituents of Azadirachta indica and Melia azedarach (Meliaceae)." Nat. Occurr. Pest. Bioregulators 449: 293-304.

[34] Charleston, D., Kfir, R., Vet, L., and Dicke, M. 2005. "Behavioural Responses of Diamondback Moth Plutella xylostella (Lepidoptera: Plutellidae) to Extracts Derived from Melia azedarach and Azadirachta indica." Bull. Entomol. Res. 95: 457-65.

[35] Senthil, N. S. 2013. "Physiological and Biochemical Effect of Neem and Other Meliaceae Plants Secondary Metabolites against Lepidopteran Insects." Frontiers in Physiology 4: 359. 